\title{
Addressing a global nursing perspective in an undergraduate nursing program: Student learning in clinical education
}

\author{
Mia Kraft, Margret Nisell \\ Department of Health Sciences, The Swedish Red Cross University College, Stockholm, Sweden
}

Received: February 7, 2018

DOI: $10.5430 /$ jnep.v8n9p45

\author{
Accepted: March 23, 2018 \\ Online Published: April 20, 2018 \\ URL: https://doi.org/10.5430/jnep.v8n9p45
}

\begin{abstract}
Objective: Although many educational student activities addressing global awareness are highlighted in the literature, the global nursing approach and how it is applied by students in clinical education is not widely described. After the implementation of a new global nursing curriculum, nursing students educated at The Swedish Red Cross University College are now engaged in counteracting inequalities in health. This paper aims to describe how nursing students apply the global nursing perspective during their clinical education.

Methods: The study is based on students' written individual reflective reports. The procedure for data analysis was inspired by a thematic and interpretive data synthesis. The four stages in Kolb's learning cycle was used as a framework.

Results: Four themes were identified: 1) Experiencing frailty, suffering and vulnerability; 2) Advocating quality of life and priorities in health; 3) Conceptualizing autonomy, involvement and participation; 4) Making a difference and acting with respect and an open mind.

Conclusions: Consequently, students at the The Swedish Red Cross University College are confident in applying global nursing perspective in care actions. Nursing educators have a mutual responsibility to facilitate students' knowledge transfers in global competencies and strategies to reduce the impact on the environment and on humans.
\end{abstract}

Key Words: Clinical education, Global nursing, Student learning, Undergraduate nursing program

\section{INTRODUCTION}

\subsection{Social awareness as a part of the global nursing per- spective}

For future nurses, it is crucial to apply a critical stance and draw attention to social awareness in nursing care actions as a part of the global nursing perspective and to advance health for all. ${ }^{[1-3]}$ In nursing education contexts, there is a great opportunity to promote global networking or global leadership and a need to emphasize globally significant nursing actions when setting aside the colonial past. A Global nursing perspective may help nurses to apply critical theories in nursing actions and identify repressive structures in nursing care as barriers for equal health care. ${ }^{[4-8]}$ Paramount areas such as economics, demographics, politics and social constitutions may determine the health of individuals, and it is necessary to emphasize broadened, globally oriented knowledge of and skills within these areas in nursing education contexts. ${ }^{[6,9]}$

It is important to explain how to construct global awareness

*Correspondence: Mia Kraft; Email: mia.kraft@rkh.se; Address: Department of Health Sciences, The Swedish Red Cross University College, Stockholm, Sweden. 
in nursing in local clinical practice contexts. To succeed with this, the collaboration between academia and the clinical setting is of vital importance. ${ }^{[10]}$ One way of improving student learning is to see the learning space as including students, patients and supervisors as a whole. ${ }^{[11]}$ However, the concept of weaving together a range of local to global student learning has been described by words such as global, international, and intercultural. ${ }^{[12]}$ Global experiences in nursing education have been engaged to develop global citizens be it in the strategic direction of the educational vision or in the curriculum that lends importance to a global approach. ${ }^{[13]}$ Global awareness has been improved through contacts in foreign contexts: a study course abroad, intercultural peer learning webinars, and global health courses locally with clinical practice in ethnic communities or with refugees. ${ }^{[2,12,14,15]}$ A few courses have been described as taking the form of internationalization at home, international health care or field experiences, international cross-cultural clinical practice, student exchange or international cultural competence immersion. ${ }^{[14,16]}$ Generally, it was found that these learning experiences developed students' cultural sensitivity, professional competence, their preparedness to care for a diverse population, their relationship building and solidarity. ${ }^{[14,17-20]}$ However, some of these studies claimed that international practice would enhance existential growth, but an understanding of global issues and global awareness is difficult to influence through a brief stay in different cultural contexts. ${ }^{[16,21]}$

\subsection{Global nursing perspective in clinical education}

To meet global challenges in nursing education at The Swedish Red Cross University College, the undergraduate nursing program was developed by implementing a global nursing approach and a global nursing curriculum. ${ }^{[5]} \mathrm{Holm}-$ gren ${ }^{[9]}$ presented a definition of the subject profile area of global nursing: "Global nursing is about developing knowledge about health, care, persons, suffering and ecology in local and global contexts. The subject profile area is characterized by advocacy, activism and sustainable development. This includes the active use of knowledge and methods that includes norm critical approaches to counteract inequalities and social injustice. Ultimately, knowledge in global nursing aims at alleviating suffering, safeguarding human dignity and contributing to health for present and future generations" (p.1).

Student learning in clinical education has the potential to contribute to a socialisation process of students into their future profession. ${ }^{[22]}$ Clinical learning can also contribute to an integration of theory and practice. In nursing education programs with a global nursing approach it is paramount to depict the holistic perspective on learning. According to Kolb's theory of experience-based learning a holistic perspective on learning is provided and combines experience, perception, cognition and behaviour ${ }^{[23,24]}$ (see Figure 1).

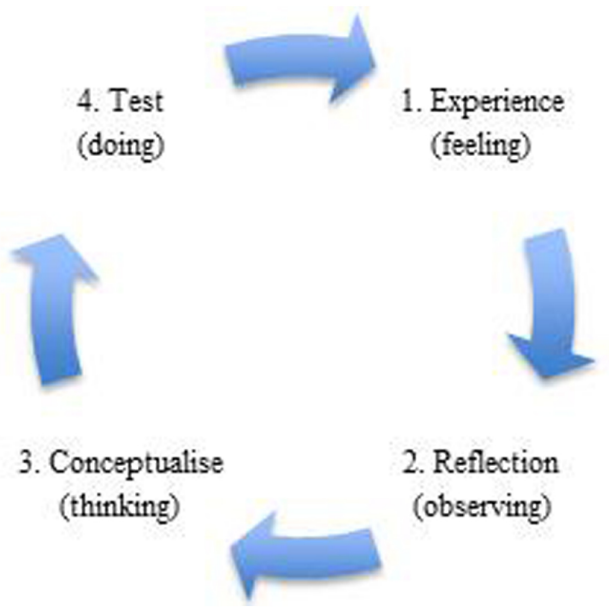

Figure 1. Kolb's learning cycle

Learning is processed by knowledge transfer and experimental learning through information processing, and is used in problem-based learning. This constructivist approach differs from behavioural learning, cognitive and behavioural theories, primarily by emphasizing the central role of experience. As shown in Figure 1, the four stages in Kolb's learning cycle are "A concrete experience", "A reflective observation", "An abstract conceptualization" and "To plan an active experimentation", and these stages must be fulfilled in order to enhance learning (see Figure 1). Nevertheless, the consensus today is to prepare future nurses to act locally and be global nurses. ${ }^{\left[{ }^{2,25]}\right.}$ However, there is a lack of descriptions of how global nursing perspective is applied in learning activities locally and in nursing actions with patients. This paper aims to describe how nursing students apply global nursing perspective during their clinical education.

\section{METHODS}

\subsection{Design}

For this study, a thematic and interpretive design was adopted to capture the nursing students' experiences. This design provides the potential to capture the way people interpret and make sense of everyday experiences. ${ }^{[26,27]}$

\subsection{The educational context}

The undergraduate nursing program consists of three academic years and leads to a bachelor degree in nursing science and a professional degree as a registered nurse. Educational activities are partly due to the tradition of The International Red Cross and its basic principles. ${ }^{[5]}$ The overall theme for

ISSN 1925-4040 E-ISSN 1925-4059 
the first year is "Health, Humanity and Caring Relations". The first semester includes relevant scientific texts about advocacy and activism, ecology, global nursing, health prevention, inequalities in health, norm critical approaches, social injustice, sustainability, the local/global binary and vulnerability. ${ }^{[3,25,28-31]}$ After the first semester, the students entered the second semester and the modules Person-centered Care and Clinical Practice with the overall revised learning objective being to gain a comprehension of both nursing science and nursing care at geriatrics or sheltered housing. To further engage students' learning, a schedule with specific and structured learning activities for the four weeks of clinical practice was constructed. In accordance with the updated design and the holistic perspective on learning by Kolb ${ }^{[24]}$ these learning activities were designed around a model of peer learning and a student-centered approach. ${ }^{[32,33]}$ Therewith, the approach of interprofessional collaboration (IPC) within a team was linked to provide skills at individual, team and organizational levels. ${ }^{[34,35]}$ Consequently, to facilitate interaction between peers, reflection was pointed out as being foundational and a method by Gibbs ${ }^{[36]}$ was provided. Contact teachers were available during the clinical practice and at a final seminar the course objectives were examined by a written individual reflective report. In this report, students reflected over their nursing actions with the patients, collaboration within the team with professionals and ethical considerations in care situations in clinical practice. A critical friends approach by Dahlgren, et al. ${ }^{[37]}$ was foundational and applied when the students reviewed the reports for each other in groups. At the final seminar with the teacher present, the reports were scrutinized and examined according to the newly designed curriculum.

\subsection{Data collection and participants}

A convenience sample of nursing students who agreed to participate in the study was asked to share their clinical education experiences in written individual reflective reports. A total of 140 students were approached, 41 agreed to participate and 38 students participated in the study, three students were excluded since they dropped out of the program. The data collection was conducted through a learning management system between August 2017 and January 2018 before the students participated in the final seminar with the teacher. The inclusion criteria were being a registered student in the nursing program at the $\mathrm{X}$ university college in semester two, and being engaged within the Module Clinical Practice. The local Board of the Student Union was contacted and a delegate from the Board communicated with the students during the first week in semester two and provided information about the study according to The World Medical Association Declaration of Helsinki Ethical Principles for Medical
Research Involving Human Subjects. ${ }^{[38]}$ All participants were informed through oral and written information before their written informed consent was given and handled by the Student Union. The participants were informed that the participation was voluntary and their identities and data would be treated confidentially. Therefore, after the data were collected, they were coded. At the time of this study, the two authors were employed as teachers at the university college, but they did not have any previous contact with the students participating in this study.

\subsection{Ethical considerations}

According to the Swedish Ethical Review Act ${ }^{[39]}$ no ethical approval was required for this study. All informants participated voluntarily and gave written consent after receiving an information letter. The informants could at any point withdraw from the study. All data were conducted confidentially and was only available to the authors. Data were stored on a laptop with a password that was not connected to the Internet during the analysis process.

\subsection{Data analysis}

The empirical material of the participants' written individual reflective reports was analyzed by using thematic and interpretive data synthesis. ${ }^{[26,27]}$ A deductive approach ${ }^{[40]}$ was adopted to structure the students' learning experiences using the four stages in Kolb's learning cycle ${ }^{[24]}$ as a framework. The empiric material was read repeatedly, separately, and discussed by the two authors to gain a sense of the reports as a whole and to develop an understanding of global nursing issues presented in each report. In the reading, the focus was on both details of accounts, the underlying meanings and the patterns in which the different words and texts depicted global nursing and also related to the four stages in Kolb's learning cycle. Then, the key findings defining global nursing were collected by the two authors from each report and listed. After this listing of key findings, the thematic and interpreted analysis went on to collate and formulate interpreted themes with their broader meanings and implications. Disagreements were resolved by concensus between the authors. Then, subthemes were identified from the interpreted themes and the thematic analysis continued by re-examining the subthemes and the four interpreted themes. In addition to the thematic analysis, the themes and subthemes were examined and discussed by the authors in relation to the organizing framework - i.e. Kolb's learning cycle. ${ }^{[26]}$

\section{RESULTS}

How nursing students apply global nursing in clinical education was illustrated in four themes: 1) Experiencing frailty, suffering and vulnerability with subthemes: Best practices 
for good health, Enhancing a holistic approach, Hierarchical care actions, Preventing frailty and suffering, and Promoting collaboration. 2) Advocating quality of life and priorities in health with subthemes: Assessing risks for health, Empowering older people, Ethical considerations, and Professional activism. 3) Conceptualizing autonomy, involvement and participation with subthemes: Considering the patient as a human being, Involvement and relationships, and Promoting autonomy. 4) Making a difference and acting with respect and an open mind with subthemes: Enhancing social awareness, Promoting openness and concienseness, and Providing respectful care actions (see Figure 2).

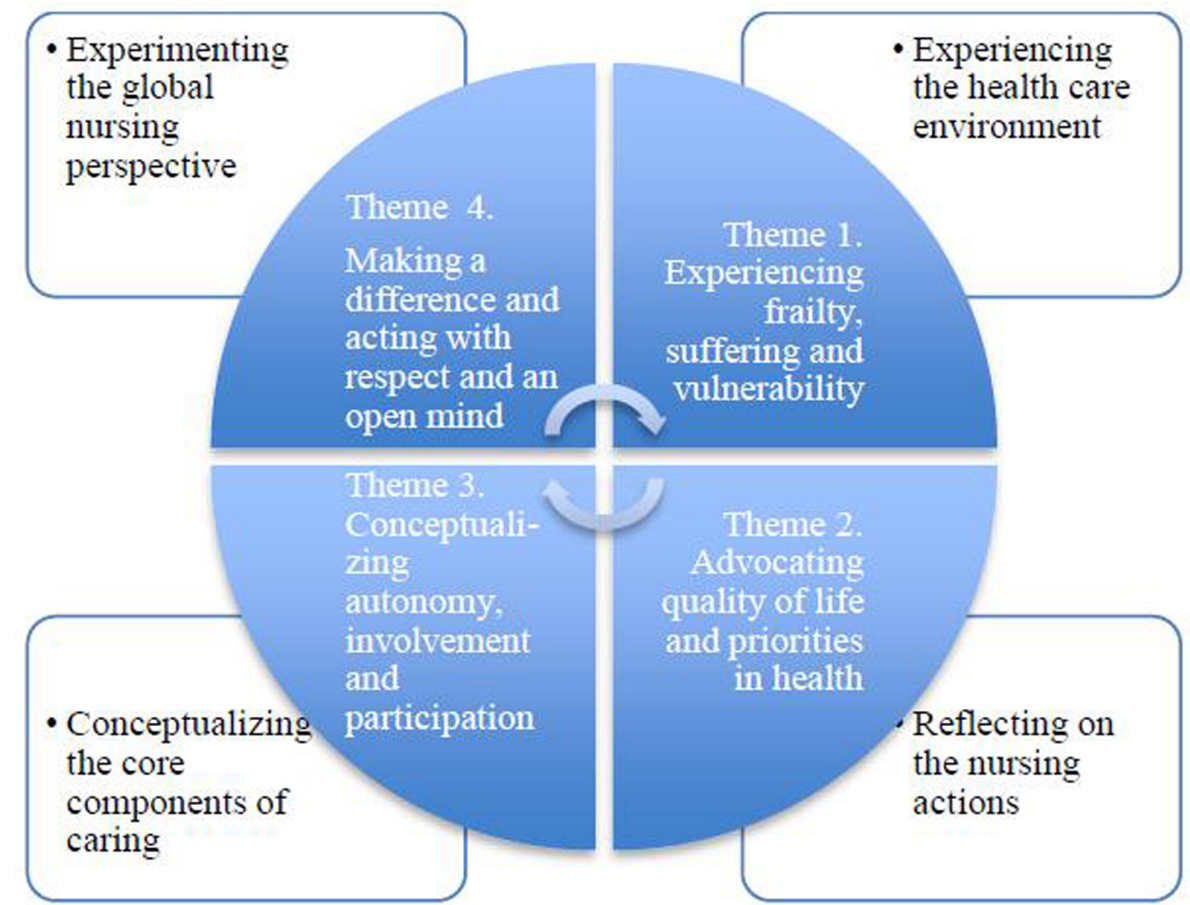

Figure 2. Overview of themes and student learning

\subsection{Theme 1. Experiencing frailty, suffering and vulner- ability}

This theme relates to how the students demonstrate awareness of the organization, the working environment and the collaboration between the professionals as being the most conditioning factors for the health of older persons. The students acknowledged that inequities in health processes could be structured and addressed by joint ethics, nursing values and holism. Global nursing was explicated in care actions related to conditioning factors on the ward, inequities in health processes, and safeguarding human potential as a core for nursing actions.

Best practices for good health. Highlighting human potential and promoting best practices were experienced as core components in nursing by the majority of the students. Nurses' professional competence and management issues on the ward were related to condition health. Through this experience, many students came to realise that the organization plays an important role and that a supportive, nonhierarchical and dynamic workplace improves nurses' pro- fessional competence.

Enhancing a holistic approach. The students experienced collaboration to focus on holism. One student explained: $O n$ the ward, the professionals have joint goals for the care and they think about the older person as a whole. However, they also practice their profession specific perspectives.

Hierarchical care actions. Vulnerability and suffering appeared in environments with hierarchical care actions without joint values in the daily work. In these cases, the students claimed it was difficult to sustain human dignity. These processes were stressed as inequities in health. One student described: Sometimes, this old woman screamed very loudly and the other patients in the dining room were disturbed. Then, the staff took this woman to her bedroom and locked the door. It was sad because she loved the company of the other older persons.

Preventing frailty and suffering. Preventing frailty and suffering was described as identifying risk factors for health. Nevertheless, some of the students reported care situations where suffering occured despite a high degree of collabora- 
tion. One student reflected: Before the surgery, this older person was able to walk long distances, but now he is too frail, tired and weak to do that. The physiotherapist and the nurse encourage and assist him, but the rehabilitation is overwhelmingly tough for him and he needs a lot of support. Another student reported: Older people suffering from dementia are the most vulnerable; they suffer from a lack of appetite and are often not able to eat.

Promoting collaboration. The majority of the students described the importance of structured collaboration within the team as being one of the major aspects contributing to good health conditions for the individuals. Joint ethics and nursing values were recognised: Every Friday the team had meetings and the professionals discussed how to improve the health of older persons living in the sheltered housing. By working together and heightening their knowledge, the professionals were able to offer the best practice and support for good health.

\subsection{Theme 2. Advocating quality of life and priorities in health}

This theme embraces the students' appreciation of nursing care and gives them an understanding of nurses' professional activism. Global nursing was elaborated in relation to nurses' ethical responsibility and moral obligations to maintain health. Nurses' interactions and relationships with older persons relate to power and subordination.

Assessing risks for health. Reflecting on priorities in health when making decisions against the older person's own wishes was described by some of the students as a valuable but difficult experience. In some of these cases, power and subordination in the relationships were understood. One student concluded: The prevention of falls on the ward is important work and often it is not a prior wish from the older person. The environment has to be fixed and modified according to the safety guidelines, but the older person does not comprehend that.

Empowering older people. The importance of activism within the nursing profession was recognised by many students as empowering older persons in discussions. The insight into nurses' care actions contributed to reflection on empowerment: According to person-centered care, it is paramount to listen to the older person and plan for the care actions together. My patient came to the hospital because she had fallen and her family members insisted that she should move to sheltered housing. It was hard to decide the best practices for her and her family.

Ethical considerations. The students' ethical considerations related to advocacy and priorities in health. Difficulties

Published by Sciedu Press in advocacy and empowerment were observed by students and were related to inequities in health. One student reflected: My patient was hard to understand and he often felt sad. It was difficult for us to handle his sadness, listen to him and to assess his care needs correctly because he could not communicate with us.

Professional activism. The students' reflections contributed to an increased understanding of person-centered care actions considered to be vital when improving quality of life. One of the students illustrated professional activism: The nurses have the responsibility for the care plans, documentation and assessing risks to health. For example, they carry out important follow-ups regarding decubitus as well as priorities for health and wellbeing.

\subsection{Theme 3. Conceptualizing autonomy, involvement and participation}

This theme relates to how the students conceptualized the core concepts of nursing. They demonstrated awareness of conditioning factors in nursing and analyzed incidents of violations and inhumanity. Situations relating to economic aspects such as nurse shortage leading to violations of autonomy were illustrated. Global nursing appeared in care situations where hierarchical, financial and social processes violated older people's autonomy, involvement and participation.

Considering the patient as a human being. The students captured nurses' professional attitudes towards caring and the central aspects conditioning older persons' life situation on the ward, such as integrity and considering the patient as a human being. Descriptions of negligence and incompetence or shortcomings amongst staff causing inhumanity in care situations influenced the daily work and were related to inequalities in health. For example, when one older person was tired and wanted to go to bed, he was not allowed to get help with that due to lack of time or the absence of staff. He was left alone in his wheelchair to sit and sleep.

Promoting autonomy. The majority of students described conflicts between good care and shortcomings in promoting older persons' autonomy, involvement and participation. One of the students explained conflicting issues in a care situation where maintaining the older person's autonomy and involvement in care decisions was insightful: My patient did not want to take off his shoes for the night and that was not so good for his feet. Nevertheless, after a long discussion with one of the nurses working the night shift, this older person could understand and make his mind up by accepting the fact that it was better for him to sleep without his shoes. Another student claimed that the main factor conditioning autonomy 
was the older person's lack of cognition. Neither the students nor the staff could handle these difficult situations where autonomy, involvement and participation were violated: It was very hard for my patient to participate and understand the care plan and the care actions planned by the team due to the severe cognitive impairment.

Involvement and relationships. To promote family involvement and participation in nursing and to further progress in this was highlighted by the majority of students. One student described the lack of nurses' engagement in these issues: According to my experiences, there are many occasions for the nurses to be better at promoting family involvement, personcentered care and how to make care decisions together with the patient and the family members. Poor relationships and lacking interaction between the older persons and the staff were described by the majority of the students.

\subsection{Theme 4. Making a difference and acting with re- spect and an open mind}

This theme relates to how the students demonstrate development in the profession and knowledge transfers in nursing such as respect and conscience that in turn are influenced by nursing values. Staying open minded in nursing care actions was perceived and developed together with the professionals. Knowledge transfers in the ability to distinguish between good and poor practices were delineated. Global nursing was explored through the recognition of the essence of nursing values and respect towards older persons and their family members.

Enhancing social awareness. The students stressed paramount knowledge transfers in global nursing activities such as enhancing social awareness, acting according to nursing values and showing respect. Almost all the students claimed that interaction with the different professionals within the nursing care actions helped them to reflect on their actual knowledge as they exchanged perceptions and thoughts. They explored the vital importance of adapting the clinic-specific care actions in these elderly care settings.

Promoting openness and concienseness. Students' openness and conscience in care activities promoting health were highlighted. All students expressed the need to test their own performance and reflected on mastering care actions and how the nurses and the other professionals acted. One student explained about this: Taking into account the social and psychosocial health needs amongst the older people is very important for me and I think the staff could advance their competence and skills in these issues. One student claimed that promoting mental health was not a prioritised area by the nurses but that the other professionals had more advanced knowledge and skills: The nurse showed a lack of engagement in mental health issues, but I collaborated with other professionals and they were competent and skilled. Incidents like this made the students question the nurses' conscience and raised doubts about what was the right thing to do.

Providing respectful care actions. Several students expressed that meeting older persons and their family members, respect and an open mind were core areas of focus in order to make a difference. One student explored the necessity for respect: My patient did not want to join the activities even though he was feeling very lonely. It was hard for me to understand that, but I respected his decision. His family members visited him often and he got quite nervous when they talked about family matters. After they left, he was sad and crying. However, they do of course have the right to visit him. Respect towards older persons in different care situations were highlighted.

\section{Discussion}

\subsection{Main results}

In the present study, the students' learning from experiences to experimenting showed that they were able to apply the global nursing perspective in care actions. The students' learning within the global nursing approach was in progress and moved between the four stages. Kolb and Kolb ${ }^{[24]}$ claim that the development of individual growth continues through successive fluctuations from one stage to another. In this study, the global nursing profile area and the new curriculum were described to provide global nursing skills at both individual, team and organizational levels. This is in line with Jogerst et al. ${ }^{[41]}$ and Wilson et al. ${ }^{[42]}$ who asserted that there is a need for best strategies for integrating interprofessional competencies into educational programs promoting global health. In our study, the learning space was seen as a whole, and an interpersonal linkage between patients, students and supervisors created the learning space for the global nursing approach and was the prerequisite for beneficial and supportive interactions, as also described by Holst, Ozolins, Brunt and Hörberg. ${ }^{[11]}$ In these kinds of relationships in real clinical environments, the students can experience authenticity with patients as active participants while student learning can be recognized as meaningful. ${ }^{[43]}$ However, as described by Holst et al., ${ }^{[1]}$ the students' learning space cannot be separated from the clinical environment and that is why student mentoring is of vital importance. ${ }^{[43,44]}$ Our interpretation is that addressing global nursing perspective in clinical education is complex with several factors interacting and stimulating student learning. As Jokelainen et al. ${ }^{[44]}$ emphasized, student mentoring enables the integration of learning and practice, and bridges the gap between theory and practice. 
We believe, that when students apply the global nursing approach in their daily work and provide care actions locally, clinical education may help them to construct the knowledge of global awareness and sustainable development in different clinical practice contexts. Accordingly, the understanding of scientific, theoretical and ethical perspectives can be both depicted and applied. This is in line with Mattsson ${ }^{[45]}$ who explained the importance of the three approaches to learning and their relationship to the given clinical education context.

How the global nursing perspective was experienced in the clinical education is described in four themes. In the first theme, global nursing relates to students' tangible experiences of conditioning factors and processes constructing hierarchies and norms in the nursing care activities. The students' knowledge was created through their experiences of human dignity as the core for nursing, and collaboration as an important factor in maintaining human potential. We claim that the social and ethical issues regarding dignity are central and should be discussed in local clinical education contexts, as depicted by Synne, Oye, Christensen and Dewing. ${ }^{[46]}$ These discussions can be carried out wherever vulnerable populations exist. ${ }^{[47]}$ It is our belief that to preserve care quality, it is important to recognize the conditions that violate or retain human dignity and when these are ignored. In our study, collaboration and best practices were important factors for providing good care. Team-specific practices are useful and of vital importance for the care quality as reported by Bridges and Fuller. ${ }^{[48]}$ However, in our experience linked to the global nursing perspective, the identification of dominant practices, hidden power relationships within best practices and silenced knowledge are also of paramount interest and should be discussed. Similarly, we maintain that students have to raise their critical voices and improve their innovativeness in these issues. Addressing specific dignityrelated concerns for older persons is one way of exercising professional activism. ${ }^{[49]}$

In the second theme, the essence of ethical responsibility and moral obligations is linked to advocacy, and integrated into the students' reflective observations. The students' knowledge was established through their experiences of nurses' professional activism. We argue that future nurses have to perform care actions in a patient-safe and non-environmental manner based on current documents and evidence-based nursing. It is our belief that including each other in a confident team in the clinical education promotes learning and makes students fearless to ask questions, which is in line with Glad, Hogvold Olsen and Clancy. ${ }^{[50]}$ We suggest that educators and supervisors raise this issue. In this study, the students acknowledged empowerment and advocacy related to global awareness in person-centered care actions. ${ }^{[51]}$ How-

Published by Sciedu Press ever, global awareness can be practiced locally even though community engagement in the students' backyard may be experienced as less operative, less fascinating, less meaningful and less urgent. ${ }^{[4]}$ Global clinical education abroad is often perceived as more exotic, different and believed to promote greater competence. We argue that successful models in clinical education will support the creation of new programs, since global/local binary in nursing is the future of care.

In the third theme, incidents of violations and inhumanity in health were perceived by thinking about and analysing nursing care problems. ${ }^{[52]}$ The students' knowledge was achieved by reviewing nurses' professional attitudes towards nursing care. Global nursing relates to students' interpretations of social and economic processes conditioning health and connected to core concepts of nursing. This is in line with Holmgren ${ }^{[53]}$ who claimed that environmental factors condition family members' involvement at nursing homes and their participation is based on certain concepts of traditional engagement. This could also influence nursing care actions and the autonomy of older persons. In our study, critical thinking and reflective learning together with the students' own experiences developed new ways of thinking in care actions and helped them to conceptualize nursing care.

In the fourth theme, the students' knowledge was generated by the need to test their own performance in meaningful caring situations. Global nursing relates to nurses conscience and makes the students reflect on nursing values and what is right or wrong. This concurs with Ericson-Lidman, Norberg, Person and Strandberg ${ }^{[54]}$ who described situations where the staff was forced to steal time from the patients or prioritize the needs of the organization and this was recognized as promoting a troubled conscience. Safeguarding dignity was also a paramount issue for the students in this study and dependent on organizational issues. As the majority of the students highlighted the importance of respect, our findings relate to Macaden, et al. ${ }^{[55]}$ who found that students were more confident about what dignity meant in practice, but could not apply theoretical aspects of dignity. Organisational, environmental, professional and personal factors were recognized as major barriers to the promotion of dignity. We argue that these cases are of vital importance.

\subsection{Methodological considerations}

The choice of methods used in the data collection and analysis will be critically described, based on different aspects related to trustworthiness. ${ }^{[56,57]}$ The credibility of a study involves aspects such as how to recruit informants, how to select key findings and how well the interpreted themes illuminate the phenomenon. Particular considerations have been taken when designing and working on the assessment 
of each phase of the analysis process. To structure the analysis, Kolb's learning cycle ${ }^{[24]}$ was applied as a framework and crucially facilitated the process. The assessment process has been taken into account through an investigation of the reflexivity of the researchers, and reliability of the data collection with appraisal in the analysis process to enhance the understanding of the findings, without conforming or violating the validity or meaningfulness of the findings. ${ }^{[56]}$ Furthermore, the dependability of the data analysis was ensured by applying the procedure of coding and formulating the interpreted themes according to relevant literature. In this study, the two authors who conducted the analysis reflected on and discussed the content and the thematization. Transferability refers to the extent to which findings can be transferred to other settings. It is also vital that sufficient thick description of the phenomenon is provided to allow readers to have a proper understanding of it. However, it is up to the reader to decide whether it is possible to transfer outcomes to other contexts. The concept of confirmability is the investigator's comparable concern to objectivity. Therefore, a detailed methodological description allows the reader to define how far the data and constructs emerging from it may be approved.

\section{CONCLUSIONS AND FUTURE DIRECTIONS}

The findings suggest that the global nursing approach improves an active use of knowledge about health, care, persons, suffering and ecology, and is suitable for students to apply in local clinical practice contexts. However, it became also evident that nursing education has to encourage students to raise their critical voices and improve their innovativeness in advocacy and professional activism. Within this study, nursing students' motivation and learning in these issues have be emphasized. Advocacy and professional activism were other concepts which constituted one of the pillars of the nursing students' knowledge and skills. This was characterized by standing up for vulnerable persons suffering from healthlessness and promoting social change when recognizing irregularities that may condition people's health negatively. It can be concluded that future nurses have to be able to explain the connection between health, illness and various aspects of sustainable development. Furthermore, nursing educators have a mutual responsibility in facilitating students' knowledge transfers in global competencies and strategies to reduce the impact on the environmental impact and on humans.

\section{ACKNOWLEDGEMENTS}

We thank The Swedish Red Cross University College, Department of Health Sciences, Sweden, for giving a grant to the corresponding researcher, which made this study possible.

\section{CONFlicts OF InTEREST Disclosure}

The authors declare that there is no conflict of interest.

\section{REFERENCES}

[1] Crigger NJ. Towards a viable and just global nursing ethics. Nurs Ethics. 2008 Jan; 15(1): 17-27. Review. PMid: 18096578. https: //doi.org/10.1177/0969733007082121

[2] Kulage KM, Hickey KT, Honig JC, et al. Establishing a program of global initiatives for nursing education. J Nurs Educ. $2014 \mathrm{Jul} 1$; 53(7): 371-8. PMid:24971731 https://doi .org/10.3928/0148 4834-20140617-02

[3] Van Herk KA, Smith D, Andrew C. Examining our privileges and oppressions: incorporating an intersectionality paradigm into nursing. Nurs Inq. 2011 Mar; 18(1): 29-39. PMid:21281393 https: //doi.org/10.1111/j.1440-1800.2011.00539.x

[4] Bradbury-Jones C. Globalisation and its implications for health care and nursing practice. Nurs Stand. 2009 Feb 25-Mar 3; 23(25): 43-7. PMid:19323125 https://doi.org/10.7748/ns2009.02.23.2 5.43.c6831

[5] Holmgren J, Kraft M. A Global Nursing Framework in The Swedish Red Cross Undergraduate Nursing Program. Nordic Journal of Nursing Research. 2017. https://doi .org/10.1177/205715851774 1268

[6] Kraft M, Kästel A, Eriksson H, et al. Global Nursing-a literature review in the field of education and practice. Nurs Open. 2017 Apr 9;
4(3): 122-133. PMid: 28694976 https ://doi .org/10.1002/no p2.79

[7] Seloilwe ES. Globalization and nursing. J Adv Nurs. 2005 Jun; 50(6): 571. PMid:15926961 https ://doi.org/10.1111/j.1365-264 8.2005.03430.x

[8] Wilson L, Mendes IA, Klopper H, et al. 'Global health' and 'global nursing': proposed definitions from The Global Advisory Panel on the Future of Nursing. J Adv Nurs. 2016 Jul; 72(7): 1529-40. PMid:27062286 https://doi.org/10.1111/jan.12973

[9] Holmgren J. Global nursing: Educating future nurses for tomorrow's nursing care needs. Nordic Journal of Nursing Research. 2017. https://doi.org/10.1177/2057158517716504

[10] Edgecombe K, Bowden B. Clinical Learning and Teaching Innovations in Nursing. Innovation and Change in Professional Education. New York: Springer, Dordrecht; 2014. 211 p. https: //doi.org/10.1007/978-94-007-7232-8

[11] Holst H, Ozolins LL, Brunt D, et al. The learning space-interpersonal interactions between nursing students, patients, and supervisors at developing and learning care units. Int J Qual Stud Health Wellbeing. 2017 Sep; 12(sup 2): 1368337. PMid: 2891870 https: //doi.org/10.1080/17482631.2017.1368337

[12] Riner M. Globally engaged nursing education: an academic program framework. Nurs Outlook. 2011; 59: 308-317. PMid: 21784495. 
https://doi.org/10.1016/j.outlook.2011.04.005

[13] Chavez F, Bender A, Hardie K, et al. Becoming a global citizen through nursing education: lessons learned in developing evaluation tools. Int J Nurs Educ Scholarsh. 2010; 7: Article 44. PMid:21194412 https://doi.org/10.2202/1548-923X.1974

[14] Carlson E, Stenberg M, Chan B, et al. Nursing as universal and recognisable: Nursing students'perceptions of learning outcomes from intercultural peer learning webinars: A qualitative study. Nurse Educ Today. 2017 Oct; 57: 54-59. PMid:28732210 https://doi .org/ $10.1016 / j$.nedt .2017 .07 .006

[15] Lenz BK, Warner S. Global learning experiences during a domestic community health clinical. Nurs Educ Perspect. 2011 Jan-Feb; 32(1): 26-9. PMid:21473478 https://doi .org/10.5480/1536 $-5026-32.1 .26$

[16] Hovland OJ, Johannessen B. What characterizes Norwegian nursing students' reflective journals during clinical placement in an African country? Int J of Africa Nurs Sc. 2015; 2: 47-52. https: //doi.org/10.1016/j.ijans.2015.03.003

[17] De Natale ML, Waltz CL. Reflections of Nursing Students Travel Abroad Experiences in Ireland: A Global Nursing Perspective. Nurs Educ Perspect. 2015 May; 36(3): 188-189. https ://doi .org/10 $.5480 / 12-862.1$

[18] Edmonds ML. The Lived Experience of Nursing Students Who Study Abroad: A Qualitative Inquiry. Journal of Stud in Internat Educ. 2010 Nov; 14(5): 545-568. https://doi.org/10.1177/1028315310 375306

[19] Kelleher S. Perceived benefits of study abroad programs for nursing students: an integrative review. J Nurs Educ. 2013 Dec; 52(12): 690-5. PMid: 24256000. https ://doi .org/10.3928/01484834 $-20131118-01$

[20] Reimer Kirkham S, Van Hofwegen L, Pankratz D. Keeping the vision: sustaining social consciousness with nursing students following international learning experiences. Int J Nurs Educ Scholarsh. 2009; 6: Article 3. PMid: 19222395. https://doi.org/10.2202/1548 $-923 \mathrm{X} .1635$

[21] Harrowing JN, Gregory DM, O'Sullivan PS, et al. A critical analysis of undergraduate students' cultural immersion experiences. Int Nurs Rev. 2012 Dec; 59 (4): 494-501. PMid:23134133 https: //doi.org/10.1111/j.1466-7657.2012.01012.x

[22] Liljedahl M, Boman LE, Fält CP, et al. What students really learn: contrasting medical and nursing students' experiences of the clinical learning environment. Adv Health Sci Educ Theory Pract. 2015 Aug; 20(3): 765-79. PMid:25312745 https://doi.org/10.1007/s1 0459-014-9564-y

[23] Kolb D. Experiential Learning [Internet]. Prentice Hall, NJ: Englewood Cliffs; 1984. [cited 2018 Jan 29]. Available from: http: //academic.regis.edu/ed205/Kolb.pdf

[24] Kolb AY, Kolb DA. Learning Styles and Learning Spaces: Enhancing Experiential Learning in Higher Education. Acad Manag Learn Edu. 2005 June; 4(2): 193-212. https://doi.org/10.5465/AMLE. 2 005.17268566

[25] Grootjans J, Newman S. The relevance of globalization to nursing: a concept analysis. Int Nurs Rev. 2013 Mar; 60(1): 78-85. PMid:23406241 https://doi.org/10.1111/j.1466-7657.20 $12.01022 . x$

[26] Evans D. Systematic reviews of interpretive research: interpretive data synthesis of processed data. Aust J Adv Nurs. 2002 Dec-2003 Feb; 20 (2): 22-6. PMid: 12537149. Available from: http://search.informit.com.au/documentSummary $; \mathrm{dn}=405497388325103 ;$ res $=$ IELHEA $>$ ISSN $: 0813-0531$

[27] Pope C, Ziebland S, Mays N. Qualitative research in health care. Analysing qualitative data. BMJ. 2000 Jan 8; 320(7227): 114-6.
PMid:10625273 https://doi.org/10.1136/bmj.320.7227.1 14

[28] Aléx L, Hammarström A. Shift in power during an interview situation: methodological reflections inspired by Foucault and Bourdieu. Nurs Inq. 2008 Jun; 15(2): 169-76. PMid:18476859 https: //doi.org/10.1111/j.1440-1800.2008.00398.x

[29] Buckner EB, Anderson DJ, Garzon N, et al. Perspectives on global nursing leadership: international experiences from the field. Int Nurs Rev. 2014 Dec; 61(4): 463-71. PMid:25411072 https ://doi.or g/10.1111/inr.12139

[30] Garner BL, Metcalfe SE, Hallyburton A. International collaboration: a concept model to engage nursing leaders and promote global nursing education partnerships. Nurse Educ Pract. 2009 Mar; 9(2): 102-8. PMid:19059008 https://doi.org/10.1016/j .nepr.2008.10 .011

[31] Hankivsky O. Intersectionality 101 report [Internet]. Canada, Institute for intersectionality research and policy, SFU. 2014 Apr [cited 2018 Jan 29]. Available from: http://vawforum-cwr.ca/sites/de fault/files/attachments/intersectionallity_101.pdf

[32] Stone R, Cooper S, Cant R. The value of peer learning in undergraduate nursing education: a systematic review. ISRN Nurs. 2013 Apr; 3. https://doi.org/10.1155/2013/930901

[33] Topping KJ. Peer assessment. Theory into Pract. 2009 Jan; 48(1): 20-27. https://doi.org/10.1080/00405840802577569

[34] Kraft M, Blomberg K, Hedman AM. The health care professionals' perspectives of collaboration in rehabilitation - an interview study. Int J Older People Nurs. 2014 Sep; 9(3): 209-16. PMid: 23384007. https://doi.org/10.1111/opn.12020

[35] Pfaff K, Baxter P, Jack S, et al. An integrative review of the factors influencing new graduate nurse engagement in interprofessional collaboration. J Adv Nurs. 2014 Jan; 70(1): 4-20. https : //doi.org/10.1111/jan.12195

[36] Gibbs G. Learning by doing: A guide to teaching and learning methods [Internet]. The Geography Discipline Network hosted by the University of Gloucestershire. 1998. Available from: http: //www2.glos.ac.uk/gdn/gibbs/index.htm

[37] Dahlgren LO, Eriksson BE, Gyllenhammar H, et al. To be and to have a critical friend in medical teaching. Med Educ. $2006 \mathrm{Jan}$; 40(1): 72-8. PMid:16441326 https://doi.org/10.1111/j.1365-292 9.2005.02349. $\mathrm{x}$

[38] World Medical Association. World Medical Association Declaration of Helsinki: ethical principles for medical research involving human subjects. JAMA. 2013 Nov 27; 310(20): 2191-4. PMid:24141714 https://doi.org/10.1001/jama.2013.281053

[39] Braun V, Clarke V. Using thematic analysis in psychology. Qual Res in Psychol. 2006; 3(2): 77-101. Available from: http://eprints . uwe.ac.uk/117354

[40] SFS 2003.460: Swedish Ethical Review Act. 2003 June [cited 2018 Jan 29]. Available from: https: //www.riksdagen.se/sv/dokument-lagar/dokument/ svensk-forfattningssamling/lag-2003460-om-etikpro vning-av-forskning-som_sfs-2003-460

[41] Jogerst K, Callender B, Adams V, et al. Identifying interprofessional global health competencies for 21st-century health professionals. Ann Glob Health. 2015 Mar-Apr; 81(2): 239-47. PMid:26088089 https://doi.org/10.1016/j.aogh.2015.03.006

[42] Wilson L, Callender B, Hall TL, et al. Identifying global health competencies to prepare 21 st century global health professionals: report from the global health competency subcommittee of the consortium of universities for global health. J Law Med Ethics. 2014 Dec; 42(Suppl 2): 26-31. PMid:25564707 https ://doi .org/10 $.1111 / j$ lme. 12184 
[43] Manninen K. Experiencing authenticity - the core of student learning in clinical practice. Perspect Med Educ. 2016 Oct; 5(5): 308-11. PMid:27638390 https ://doi.org/10.1007/s40037-016-029 4-0

[44] Jokelainen M, Turunen H, Tossavainen K, et al. A systematic review of mentoring nursing students in clinical placements. J Clin Nurs. 2011 Oct; 20(19-20): 2854-67. PMid:21429055 https ://doi.or $\mathrm{g} / 10.1111 / \mathrm{j} .1365-2702.2010 .03571 . \mathrm{x}$

[45] Mattsson J. Improving Academic Writing in Nursing Education. Int J of High Edu. 2016 Oct; 4(5): 96-102. https ://doi .org/10.5 430/ijhe.v5n4p96

[46] Synne O, Oye C, Christensen K, et al. Raising the question of dignity through knowledge about tacit practices and politics: sharing learning from the Norwegian welfare state. Int Pract Devel J. 2017; (Suppl 1): 1-6. https://doi.org/10.19043/ipdj.7SP.001

[47] Rowthorn V. Global/Local: What Does It Mean for Global Health Educators and How Do We Do It? Ann Glob Health. 2015 Sep-Oct; 81(5): 593-601. PMid:27036715 https://doi.org/10.1016/j. aogh.2015.12.001

[48] Bridges J, Fuller A. Creating learning environments for compassionate care: a programme to promote compassionate care by health and social care teams. Int J Older People Nurs. 2015 Mar; 10(1): 48-58. PMid:24849082 https ://doi.org/10.1111/opn.12055

[49] Harstäde CW, Blomberg K, Benzein E, et al. Dignity-conserving care actions in palliative care: an integrative review of Swedish research Scand J Caring Sci. 2017 May; 1-16. https ://doi .org/10.111 $1 /$ scs. 12433

[50] Glad T, Høgvold Olsen T, Clancy A. Promoting nursing competence in municipal healthcare services: An interview study of ex- perienced nurses' perceptions. Nordic J of Nurs Res. 2017. https : //doi.org/10.1177/2057158517721833

[51] Ekman I, Swedberg K, Taft C, et al. Person-centered care-ready for prime time. Eur J Cardiovasc Nurs. 2011 Dec; 10(4): 248-51. PMid:21764386 https://doi.org/10.1016/j.ejcnurse. 201 1.06 .008

[52] Cavanagh SJ, Hogan K, Ramgopal TL. The assessment of student nurse learning styles using the Kolb Learning Styles Inventory. Nurs Educ Today. 1995; 15(3): 177-183. PMid: 7616940. http: //dx.doi .org/10.1016/S0260-6917(95)80103-0

[53] Holmgren J. A Visual analysis on how the Physical Environment Conditions Relatives' Involvement in Nursing Homes. SAGE Open. 2017 Oct-Dec; 1-10. https://doi.org/10.1177/2158244017 740398

[54] Ericson-Lidman E, Norberg A, Persson B, et al. Healthcare personnel's experiences of situations in municipal elderly care that generate troubled conscience. Scand J Caring Sci. 2013 Jun; 27(2): 215-23. PMid:22612532 https : //doi.org/10.1111/j.1471-6712.20 $12.01017 . \mathrm{x}$

[55] Macaden L, Kyle RG, Medford W, et al. Student nurses' perceptions of dignity in the care of older people. Br J Nurs. 2017 Mar 9; 26(5): 274-280. PMid:28328265 https://doi .org/10.12968/b jon. 2017.26.5.274

[56] Sandelowski M. Rigor or rigor mortis: the problem of rigor in qualitative research revisited. ANS Adv Nurs Sci. 1993 Dec; 16(2): 1-8. PMid:8311428 https : //doi.org/10.1097/00012272-199 312000-00002

[57] Rolfe G. Validity, trustworthiness and rigour: quality and the idea of qualitative research. J Adv Nurs. 2006 Feb; 53(3): 304-10. Review. https://doi.org/10.1111/j.1365-2648.2006.03727.x 